Egyptian Journal of Aquatic Biology \& Fisheries

Zoology Department, Faculty of Science,

Ain Shams University, Cairo, Egypt.

ISSN 1110-6131

Vol. 24 (1): 219 - 231 (2020)

www.ejabf.journals.ekb.eg

\title{
Embryonic development of the rabbit fish Siganus rivulatus and allometric growth patterns during yolk sac larvae stage produced by hormone-induced broodstock
}

\author{
Amal F. Fahmy* and Olfat M. Wahbi \\ Laboratory of Fish Reproduction and Spawning, Aquaculture Division, National Institute of \\ Oceanography \& Fisheries (NIOF), Alexandria, Egypt \\ *Corresponding Author: aml.fayez2017@gmail.com
}

\begin{abstract}
The embryonic development of the rabbitfish Siganus rivulatus produced from induced spawning broodstock is described under controlled laboratory conditions. The present work studied the embryonic development of the laboratory reared Siganus rivulatus from eggs to yolk sac larval stage after high dose of hormonal induction with $100 \mu \mathrm{g} \mathrm{kg}^{-1}$ of leuteinizing hormone releasing hormone (LHRHa) injection as the best dose for egg quality (baseline). This research was conducted to study the differences in the growth pattern during the yolk sac larval stage between two experiments $100,50 \mu \mathrm{g} \mathrm{kg} \mathrm{g}^{-1}$ as high and low dose of LHRHa injection that whereby recognize the appropriate dose for seed quality produced. Embryonic stages of Siganus rivulatus were observed. The morphometric parameters which were measured in larvae included: total length (TL), head length (HL), trunk length (TrL), head trunk length [pre-anal length (PreAl)] and tail length (TaL). Also, the Post-anal to Pre-anal ratio was calculated for each experiment. The allometric growth patterns were calculated by a power function of total length (TL) and describing the relation between every character $(\mathrm{Y})$ by the growth coefficient $(\mathrm{b}),\left(\mathrm{Y}=\mathrm{aTL} \mathrm{L}^{\mathrm{b}}\right)$. The seven embryonic developmental periods (stages) which were studied included: fertilized eggs, cleavage, morula, blastula, gastrula, segmentation and hatching stages. The mean total length of the newly hatched larvae was $1.975 \mathrm{~mm}$ and increased linearly until the end of the experiments with a high correlation and regression coefficient in both injected groups. Before the onset of exogenous feeding, there was a clear growth priority in the head region in relation to total length in larvae of the high dose treated group. Tail region had strong positive allometric growth in larvae of both injected groups; with faster larval growth rate in those of the high dose injected group. In conclusion the differences in the growth rate were directly proportional to the dose of injection.
\end{abstract}

\section{INTRODUCTION}

Rabbitfish family Siganidae, is one of the most abundant fish inhabiting Red and Mediterranean seas. Recently, it received great attention as it can be cultivated successfully with mullets and milkfish as well Mehanna et al. (2018). One of the main interests of seed production and hatchery system is to produce the maximum quality of fingerlings. Egg size is an important consideration for egg and larval quality during incubation and rearing in aquaculture. Identifying egg quality is the best method of predicting larval quality under experimental conditions or standard commercial scale that would avoid economic loss Rideout et al. (2004). Wahbi et al. (2017) found that eggs and larval quality recorded 
increased values in the group injected with hormones. The studies on embryonic development became connected to the successful rearing of larvae for large scale seed production and to achieve the best of larval growth and survival (Marimuthu and Haniffa, 2007). Therefore, the study of early embryonic development and allometric growth patterns in marine cultured fishes are used as a tool-guide and can direct efforts of fish producers to the specific state and requirements of each stage for proper management in aquaculture industry MartínezMontaño (2014). These studies can be useful for improving the quality of fish produced during the early growth and help to identify any abnormal deformities that may occurr (Khemis et al. 2013; Asgari et al. 2013a, 2013b; Asgari et al. 2014). Tabugo et al. (2013) described the embryonic developmental processes of eggs and newly hatched larvae of rabbitfish Siganus guttatus under desirable conditions. Fahmy (2019) improved the spawning activity and egg quality (including egg diameters, latency time, total number of spawning fertilized eggs, fertilization and hatching rate) of Siganus rivulatus using high doses (100 $\mu \mathrm{g}$ $\mathrm{kg}^{-1}$ ) of luteinizing hormone releasing hormone analogue (LHRHa) injection. Studying the embryonic and larval development are key steps to enhance development and maximize survival (Puvaneswari et al., 2009). The larval development may be influenced by the environment (Gilbert and Bolker, 2003). At hatching, most of the functional systems in larvae are incomplete. Thus, these larvae require developing quickly the most essential organs and systems (i.e. feeding, respiration and locomotion) for primary functions to survive. The study of growth pattern may allow better understanding the priorities during early growth in the early life stages (Gisbert,1999). Moshayedi (2017) showed the corresponding relation of the body shape growth larval stages based on effective various morphological changes. During the first developmental stages of fish, there is a noticeable difference in relative energy allocation to growth or metabolic processes (Parra and Yu'fera, 2001). So, the allometric growth patterns of some parts of the body during early larval development is due to its vital structures which related to important functions and considered an adaptive response to the environmental conditions that may affect the probability of survival rate of larvae and growth performance (Osse and Van-den Boogaart, 1995; Asgari et al. 2013a). Çoban et al. (2012) calculated the allometric growth patterns as a power function of total length using the growth coefficient to find the important steps in early life history to promote the development of optimal rearing protocols. Hasanpour et al. (2015a) emphasised that the allometric development is most essential for primary functions organs in the early larval stages associated with development of feeding apparatus, swimming, respiration and sense organs to optimize their survival followed by the development of organs with lower priority for survival. With the onset of yolk sac depletion during development, internal morphological changes occurred to determine the physiological and behavioral capabilities. These changes were successful in optimizing the efficiency of prey capture and increase escape from predators of early life fish survival (Comabella $\boldsymbol{e t}$ al., 2013). The present work studied the embryonic developmental stages of Siganus rivulatus from fertilized eggs to yolk sac larval stage after only high dose of hormonal injection at a dose of $100 \mu \mathrm{gg}^{-1}$ LHRHa as a baseline for successful development.

The aim of the present work is to identify the differences in the growth pattern during the yolk sac larval stage between two experiments $100,50 \mu \mathrm{gg}^{1}$ as high and low dose of LHRHa injection and to determine the appropriate dose for best growth rate and seed quality produced.

\section{MATERIAL AND METHODS}

The broodstocks of Siganus rivulatus were selected from capture stock at the prespawning season (April 2017) from Northwestern Mediterranean Coastal regions in 
Alexandria, Egypt. The broodstock samples were transported with well aerated seawater tanks to the research unit in Marine Hatchery at National Institute of Oceanography and Fisheries (NIOF). Eighteen fish were selected and divided into two groups. The first group received high dose $\left(100 \mu \mathrm{g} \mathrm{kg}^{-1}\right)$ of LHRHa injection while the second group received low dose (50 $\mu \mathrm{g}$ $\left.\mathrm{kg}^{-1}\right)$. The two groups were stocked with control sex ratio (2 males: 1 female). The fertilized eggs and embryonic stages were obtained from artificial propagation of a hormonally-induced spawning of Siganus rivulatus after only high dose LHRHa hormonal injection (100 $\left.\mu \mathrm{gg}^{-1}\right)$; as the best dose for egg quality, Fahmy (2019).

\section{Egg incubation and larval rearing}

In the two injected experiments, all injected fish were ovulated, spermiated and spawned. Fertilized eggs from both injected groups were transferred immediately from spawning tanks by an egg collector (mesh $100 \mu \mathrm{m}$ ), washed with sterile seawater and placed in 150 liters incubating hatching tanks at $25{ }^{\circ} \mathrm{C}$ ad $39 \mathrm{~g} \mathrm{~L}^{-1}$. Unfertilized or opaque eggs were removed to avoid any contamination. Water was changed at least three times during incubation to provide optimal rearing conditions. The newly-hatched larvae from both injected groups were transferred and placed in two triplicate (100- liters) of circular rearing fiberglass tanks (50 individuals per liter, depth $=1.2 \mathrm{~m}$ ) connected to a flow-through fresh seawater system.

\section{Sampling for embryonic development}

The embryonic development of the fertilized eggs produced from the broodstocks which received only high dose $\left(100 \mu \mathrm{gg}^{-1}\right)$ of LHRHa injection was studied. The egg size of 10 randomly selected eggs was measured using a micrometer lens in Olympus research microscope. Samples of the fertilized eggs were transferred into a beaker $(500 \mathrm{ml})$ and collected 10 samples for embryonic development observations at 30-min intervals for the first 24 hours and then every hour until hatching. Eggs were observed from spawning to hatching under an Olympus research microscope after 10 to 15 minutes to recognize the blastodisc as an indication of fertilization success. Developmental time post fertilization was rounded to the nearest minute until the morula stage and then to the nearest hour. The observations were carried out and photographs were taken. Embryonic developmental stages were identified according to Kimmel et al. (1995).

\section{Samples for larval measurements}

After hatching and until the onset of feeding (4 days post hatching, DPH) daily random samples of 10 larvae were taken from each injected groups and were anesthetized with Clove oil. The larvae were sampled and photographed using a stereomicroscope equipped with Cannon camera with a 5 MP resolution. Some_morphometric characters including total length (TL) form the tip of the snout to the end of the caudal fin, head length (HL) from the tip of the snout to the end of the operculum, trunk length (TrL) from the end of the operculum to the anus, post anal length (POAL), pre-anal length (PreAL) were measured. Also, post-anal to preanal length ratio was calculated and the measurements were taken by microscopic micrometer to the nearest $0.01 \mathrm{~mm}$. Also the study of the morphometric ratios $(\mathrm{R})$ of all the characters $(\mathrm{Y})$ to total length (TL), calculated as $\mathrm{R}=\mathrm{Y} / \mathrm{TL}$ (Koumoundouros $\boldsymbol{e t}$ al., 1999) were performed during development to identify the alteration of R-values with TL in relation to the allometric growth of the body. All characteristics were measured along the lines parallel or perpendicular to the horizontal axis of the body. Measurement method followed (Leis and Trnski, 1989). 


\section{Statistical analysis of the data}

Data were analyzed using IBM SPSS software package version 21.0 (Chicago, IL.USA). Student t-test was applied to compare the differences between the egg diameters and the total length of newly hatched Siganus rivulatus yolk sac larvae parentally injected with the two hormonal levels. The correlation between egg diameters and larval length from both experiments were used. Data were expressed as mean \pm SD and the significances of results were judged at the $1 \%$ level. Pearson coefficient was used to correlate between quantitative variables. The growth patterns during the early development were modeled by a power function of total length (TL) and describing the relation between every character (head length, trunk length, pre-anal length and tail length) with total length by $\mathrm{Y}=\mathrm{aTL} \mathrm{L}^{\mathrm{b}}$, $\mathrm{a}$ is the intercept and $\mathrm{b}$ described the growth coefficient (Fuiman, 1983) when $b=1$, isometric growth occurred, allometric growth was positive when $b>1$ and negative when $b<1$. The growth patterns were calculated by linear regression analysis using total length as an independent variable. Growth coefficients were compared statistically using the t-test. The morphometric ratios $(\mathrm{R})$ of all the characters $(\mathrm{Y})$ to the total length were calculated by: $\mathrm{R}=\mathrm{Y} / \mathrm{TL}$ (Koumoundouros et al., 1999).

\section{RESULTS}

\section{Embryonic development}

In the present study fertilized eggs of rabbitfish Siganus rivulatus have a mean diameter of $0.641 \pm 0.03 \mathrm{~mm}$. They were tiny spherical in shape and transparent in appearance. The fertilized eggs of Siganus rivulatus contain several oil globules. These globules appeared in the middle of the egg with average 7-15 globules and diminish during ontogenesis due to its fusion. The first cleavage in the early stage of embryo development is characterized by synchronized discoidal cleavage, occurring only in the blastodisc. Blastodisc is a thin region of Non-yolky cytoplasm toward the animal pole of the egg. A vertical furrow divides the blastodisc to form two equal blastomeres passing only the blastodisc and not through the yolky region of the egg, Figure 1a. Early cleavage divisions are rapid and taking about 15 minutes each. The second cleavage occurred and four blastomeres are clearly observed, Figure $1 \mathrm{~b}$. The following several cleavages are strictly oriented relative to the first one. At morula stage, successive cleavage occurs, blastomeres become crowded cells and blastodisc begins to look ball-like, after $2^{1 / 2} \mathrm{hrs}$ at the 128-cells, Figure 1c. When embryo enters midblastula transition (MBT), epiboly begins and expanded over the yolk and the division was asynchronous. The cleavage patterns observed from 2 to 3 hours post fertilization. From onset of gastrulation, the epiboly of the blastoderm cells moved more from the animal pole to cover the part of the yolk cell, (Figure 1d) and 30\% epiboly was observed after 4 hours from spawning. Eventually, at the end of the gastrula period, the yolk cell becomes engulfed completely. Thereafter, the movement of cells, convergence and extension continues and a thickened marginal area around the yolk forming the germ ring and embryonic shield appears almost simultaneously, Figure 1e\&f. The segmentation period was characterized by the sequential formation of the somites, rudiments of the primary organs, prominence of tail bud and embryos elongation, Figure 1g. Afterward the cephalic and caudal regions of the embryo became distinct, Figure 1h. During this period, the brain differentiation and eye development have taken place. At pre-hatching stage, the embryo shows conspicuous muscular contractions and the fat globules begin to fuse, Figure 1i. The hatching process occurred asynchronously around $22-24 \mathrm{~h}$ after spawning at $22 \pm 0.5^{\circ} \mathrm{C}$. The embryonic development was completed at $24 \mathrm{~h}$. 

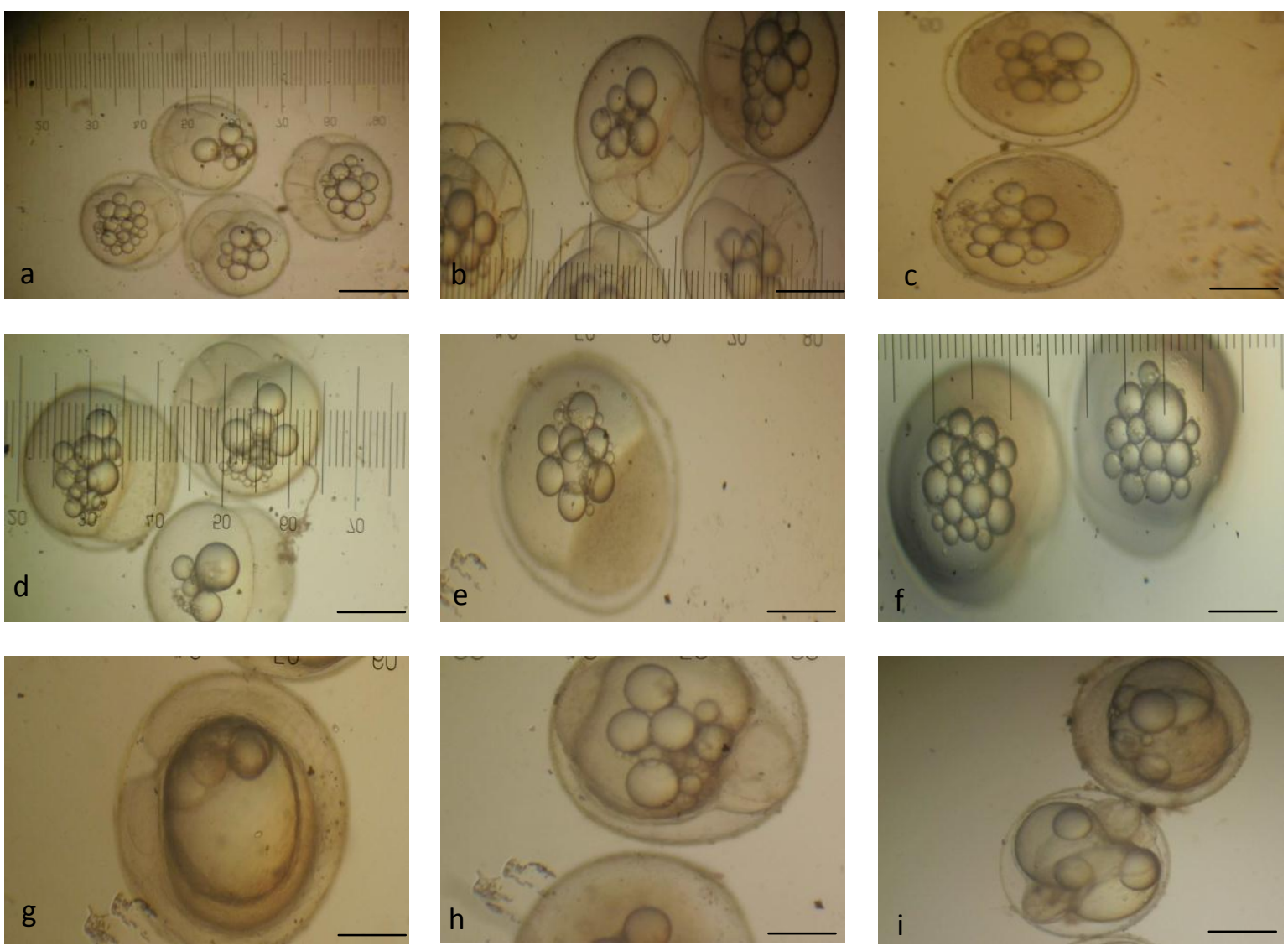

Figure 1. The stages of embryonic development in Siganus rivulatus after induced spawning with $100 \mu \mathrm{gg}^{-1}$ LHRHa treatment of broodstock fish. (a) 2-blastomere stage ; (b) 4-blastomere stage; (c) Morula stage (d) gastrula stage; (e) \& (f) germ ring and embryonic shield formation; (g) Segmentation period; (h) embryo inside;

(i) Pre-hatching stage; Scale bars, 100 micron

\section{Larval Development}

\subsection{Morphological observations}

- Newly hatched larvae (TL: $1.975 \pm 0.5 \mathrm{~mm}$ )

The body of the newly hatched larvae was transparent and lacked all major organs and systems, Figure $2 \mathrm{a}$. The mouth and anus were still closed when the yolk sac was $20 \%$ of the total body length. The eyes were un-pigmented and the digestive tract was an undifferentiated tube in the dorsal posterior region of the yolk sac. A single oil globule was present in the anterior lower region of the yolk sac.

- 1-2 days post hatching (DPH): TL: 2.40 - $2.49 \mathrm{~mm}$

From the first period, the larvae were characterized by a straight tube undifferentiated alimentary tract. The mouth and anus were still closed. Eyes were not pigmented and no fins were differentiated. The oval-shaped swim bladder was observed. The yolk sac was ovoid and still occupied almost $15 \%$ of the total body length, Figure $2 \mathrm{~b}$. At the yolk-sac larva stage, there was a change in the oral region and shifted from a ventral to a terminal position. 
- 3-4 days post hatching (DPH): TL: $2.61-2.76 \mathrm{~mm}$

At the beginning of this period, the digestive tract was developed with mouth and anus openings, Figure 2c. By this time the yolk sac was almost absorbed and larvae started to get exogenous feed. There was only a small oil globule left and the larvae started to swim freely. The eyes were fully pigmented and the larvae have primordial fins; pectoral and caudal fins, Figure 2c.

$\mathbf{a}$

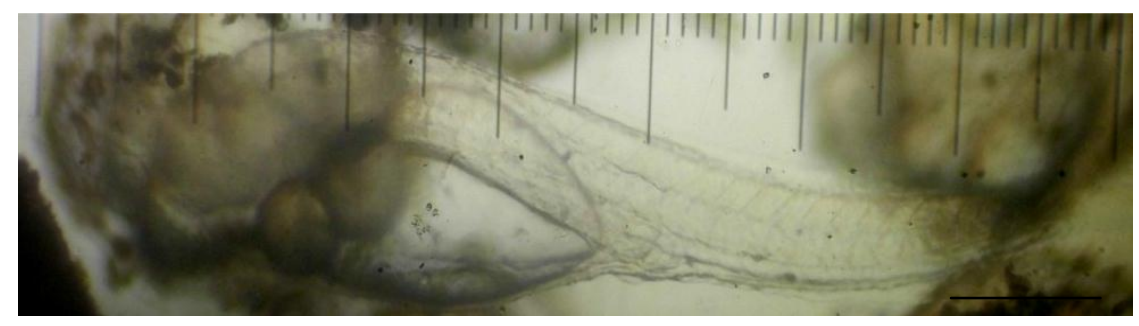

b

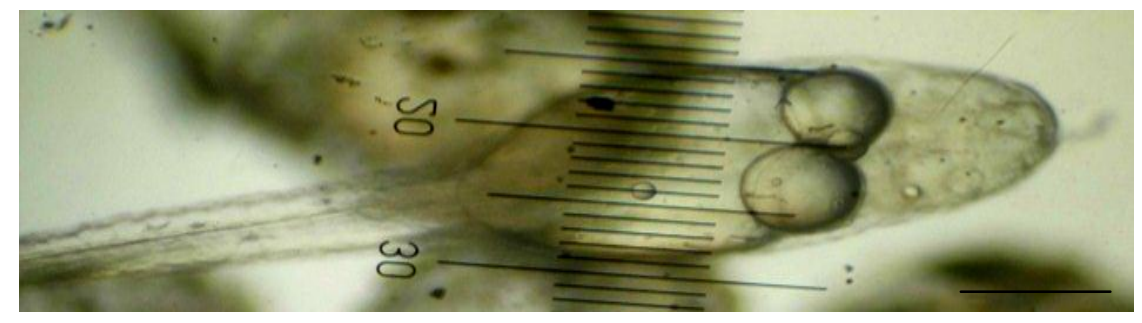

c

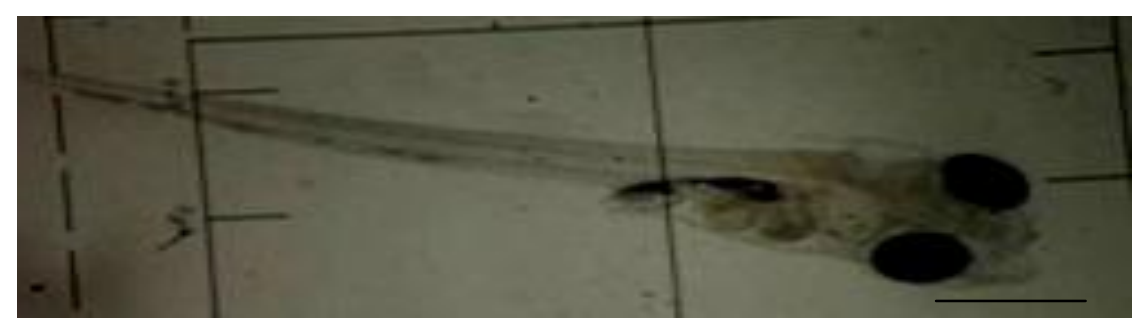

Figure 2. Larval development of Siganus rivulatus: (a) newly hatched larvae (1 h); (b) yolk-sac larval stage (2 days old larvae -opened-mouth stage); (c) Four days old larvae (at beginning of exogenous feed). Scale bars a $\& b=100$ micron, $c=50$ micron

\subsection{Larval quality}

The effects of hormonal injections on the egg diameter and larval lengths are shown in table1. There was a highly significant difference in egg diameter between the two groups receiving 50 and $100 \mu \mathrm{gg}^{-1}$ of LHRHa, Table 1 . Moreover, the total length $(1.98 \mathrm{~mm})$ of newly hatched yolk-sac larvae produced from broodstocks receiving high dose of LHRHa was highly significant difference from the total length $(1.59 \mathrm{~mm})$ of newly hatched yolk-sac produced from broodstocks receiving low dose of LHRHa (Table 1). On the other hand, a highly positive correlation was established between egg diameters and total larval lengths at yolk sac larvae stage produced from broodstock receiving high hormonal dose (100 $\mu g \mathrm{~kg}^{-1}$ LHRHa) as shown in Table 2. 
Table 1. Egg diameter, total length of newly hatched Siganus rivulatus yolk sac larvae parentally injected with different hormonal levels

\begin{tabular}{l|c|c}
\hline \multicolumn{1}{c|}{ Doses } & Egg diameter $(\mathbf{m m})$ & Total length $(\mathbf{m m})$ \\
\hline $\mathbf{1 0 0} \boldsymbol{\mu g}$ & $0.64 \pm 0.03$ & $1.98 \pm 0.2$ \\
\hline $\mathbf{5 0} \boldsymbol{\mu g}$ & $0.58 \pm 0.01$ & $1.59 \pm 0.1$ \\
\hline $\mathbf{P}$ & $<0.001^{*}$ & $<0.001^{*}$ \\
\hline${ }^{*}$ Significant at $\mathrm{p} \leq 0.01$ &
\end{tabular}

Table 2. Correlation of egg diameter with total length of Siganus rivulatus yolk sac larvae at different parental hormonal injections

\begin{tabular}{l|c|c}
\hline \multicolumn{3}{c}{ Egg diameter $(\boldsymbol{\mu m})$} \\
\hline Doses & $\mathbf{1 0 0} \boldsymbol{\mu g}$ & $\mathbf{5 0} \boldsymbol{\mu g}$ \\
\hline Total length $(\mathbf{m m})$ & & \\
$\mathbf{r}$ & 0.9844 & 0.8934 \\
$\mathbf{p}$ & $0.001^{*}$ & $0.001^{*}$ \\
\hline
\end{tabular}

*Significant at $\mathrm{p} \leq 0.01$

r: Pearson coefficient

\subsection{Larval growth}

The total length of the Siganus rivulatus yolk sac larvae showed a significant difference after the first days of hatching (1 DPH - 4 DPH) between the injected groups 50, $100 \mu \mathrm{gg}^{-1}$ LHRHa, Table 3. Moreover, the total lengths had increased linearly from hatching in both injected groups during the experimental period regardless of the injection dose. There were strong relationships between the total length and the age in both treated groups, Figure 3.

Table 3. Total length of Siganus rivulatus yolk sac larvae produced from brrodstock injected with different hormonal levels

\begin{tabular}{l|ccccc}
\hline Doses & \multicolumn{5}{|c}{ Total length(mm) } \\
\cline { 2 - 6 } & $\begin{array}{c}\text { Newly } \\
\text { hatched }\end{array}$ & $\mathbf{1 D P H}$ & $\mathbf{2 D P H}$ & $\mathbf{3 D P H}$ & 4DPH \\
\hline $50 \mu \mathrm{g}$ & $1.59 \pm 0.02$ & $1.72 \pm 0.0$ & $2.25 \pm 0.0$ & $2.32 \pm 0.06$ & $2.43 \pm 0.07$ \\
\hline $100 \mu \mathrm{g}$ & $1.98 \pm 0.01$ & $2.41 \pm 0.04$ & $2.49 \pm 0.03$ & $2.60 \pm 0.02$ & $2.76 \pm 0.05$ \\
\hline $\mathrm{P}$ & 0.065 & $0.009^{*}$ & $0.010^{*}$ & $0.0003^{*}$ & $0.00018^{*}$ \\
\hline
\end{tabular}

Significant at $\mathrm{p} \leq 0.01, \mathrm{DPH}$ : Days Post Hatching

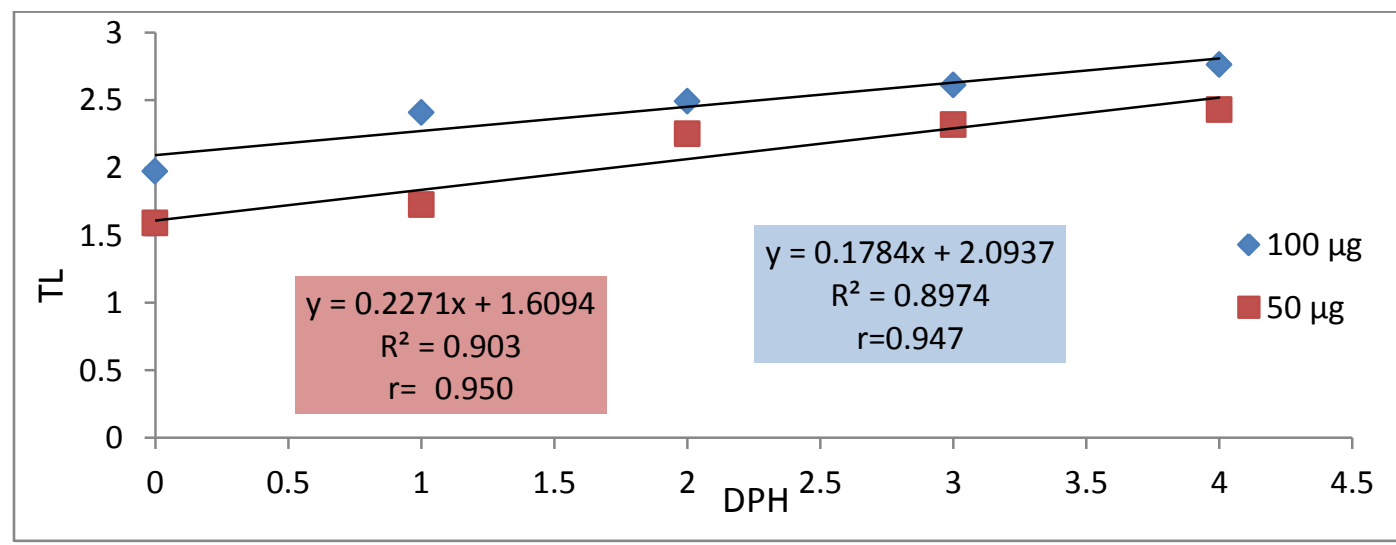

Figure 3. Linear regression between total length (TL) (mm) and days post hatching (DPH) of laboratory-reared larvae Siganus rivulatus at yolk sac larval stage produced from broodstock injected with the two hormonal doses. 


\subsection{Allometric growth of yolk-sac stage larvae produced from two doses of induced spawning broodstock Siganus rivulatus}

In the yolk-sac stage and during the endogenous nutrition period, positive allometric growth was found for the head and tail length in relation to total length at the high injected group (100 $\mathrm{g} \mathrm{kg}^{-1}$ LHRHa ) during the experimental time (0 DPH- $\left.4 \mathrm{DPH}\right)$, Figure 4a. Growth coefficient of the head showed strong positive allometric growth $\left(b=1.8161, R^{2}=\right.$ 0.7516) in yolk-sac stage larvae produced from broodstocks Siganus rivulatus treated with the high concentration (100 $\mu \mathrm{gg}^{-1}$ LHRHa) while second group of broodstocks treated with the low concentration dose (50 $\mu \mathrm{g} \mathrm{kg}^{-1}$ LHRHa) produced yolk-sac stage larvae with negative allometric growth coefficient of head $\left(b=0.0738, R^{2}=0.7822\right)$ (Figure $\left.4 b\right)$.
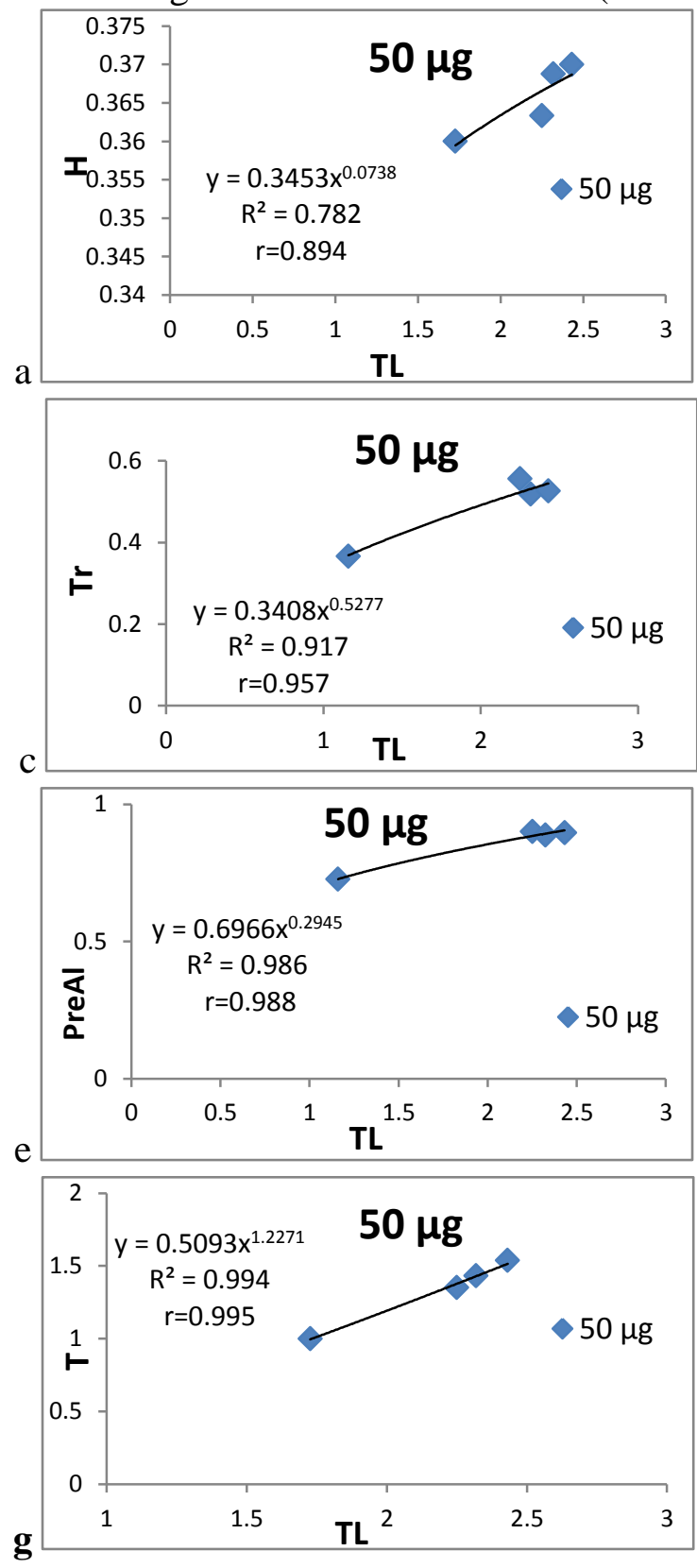

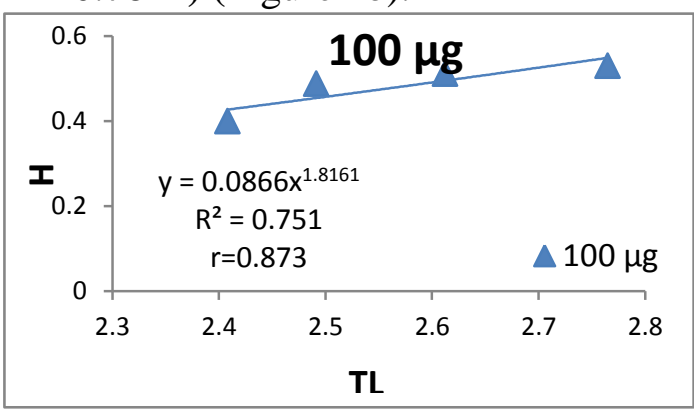

b
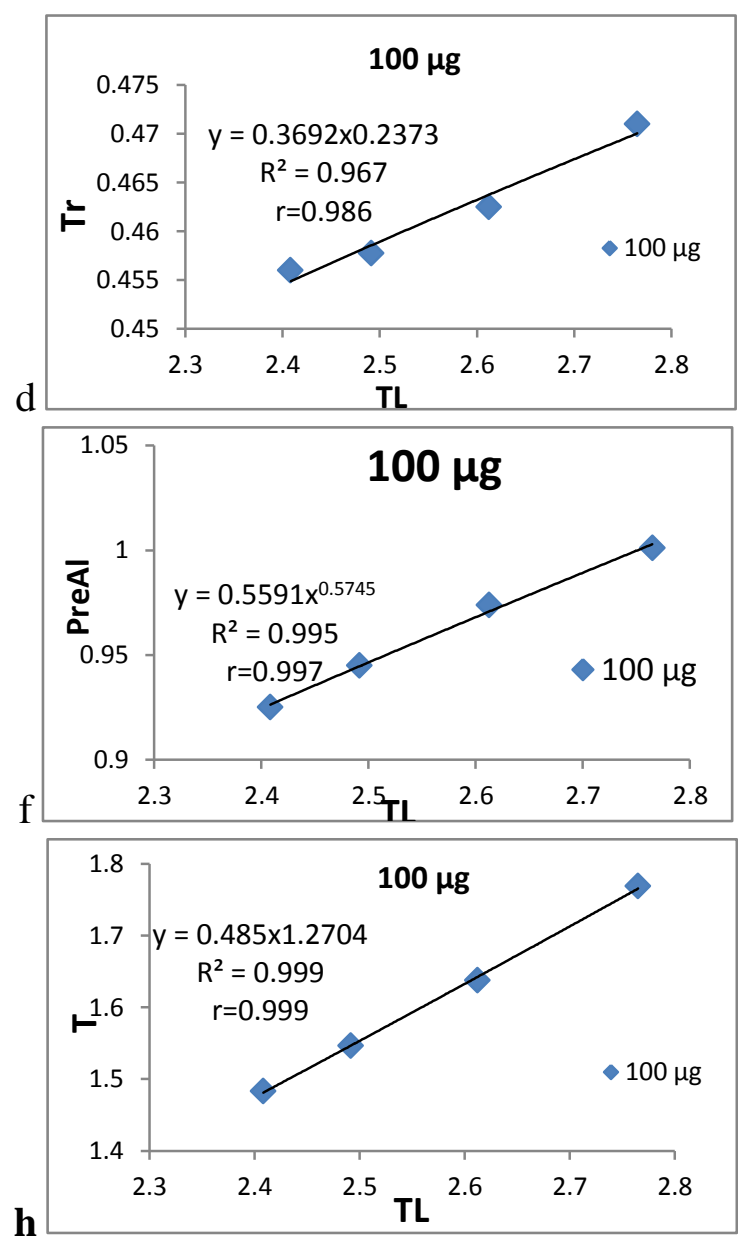

Figure 4. Allometric growth regression lines between body segments variables. $(a, b)$ head length $(\mathrm{H}),(\mathrm{c}, \mathrm{d})$ trunk length $(\mathrm{Tr}),(\mathrm{e}, \mathrm{f})$ Pre-anal length (PreAl), (g,h) Tail length (T), relative to Total length (TL) of Siganus rivulatus during the yolk-sac larva stage produced from broodstock spawned with 50 and $100 \mu \mathrm{gg}^{-1}$ LHRHa. 
Trunk length growth showed the same trend at early larvae in both concentrations. Strong negative allometric growths were observed throughout the yolk-sac larval stage produced from both broodstocks treated with high or low doses, Figure 4c\&d. The growth pattern of the Pre-anal length (PreAl) was allometrically negative at yolk sac larvae in both treated groups, Figure 4e\&f. The pre-anal length growth coefficient in high concentration dose group was faster than the growth coefficient of low concentration dose $\left(b=0.5745, R^{2}=\right.$ 0.9956 and $b=0.2945, R^{2}=0.9866$ respectively. The growth coefficient of tail length was positively allometric growth in relation to total length of yolk-sac stage larvae produced from both broodstocks treated with high or low doses (Figure $4 \mathrm{~g} \& \mathrm{~h}$ )

During the yolk-sac larva stage, head allometry was significantly negative in low dose and head length proportion decreased on average from $20.8 \%$ to $15.2 \%$ of the total length through the first four days of the experiment, Table 4 . While the head length of the yolk-sac larvae produced from broodstocks treated with the high concentration, had $18.6 \%$ of the total length in day 1 and increased with growth reaching $19.16 \%$ of the total length at the end of the larvae yolk sac stage, Table 4. The trunk length ratio to the total length of the yolk-sac larvae produced from broodstocks treated with low concentration was increased continuously up the end of the experiment from $21.2 \%$ in day 1 until reached $21.6 \%$ at the end of the larvae yolk sac stage. While the trunk ratio to the larval total length was slightly decreased from $18.9 \%$ to $17 \%$ at the end of the larvae yolk sac stage produced from treated broodstocks with high dose of injection, Table 4. Furthermore, pre-anal length ratio to the total length of larvae produced from broodstocks treated with low concentration had slight continuous decrease up to the end of the experiment $42.1 \%$ to $36.8 \%$. In contrast, broodstocks treated with high concentration, the pre-anal length ratio to the total length of larvae produced were characterized by more or less constant ratio, Table 4. Post anal length (PoAl) ratio to the total length of larvae showed a continuous progress up to the end of the experiment in all larvae produced from both broodstocks treated groups, Table 4. Moreover, the ratio between the post-anal length to the pre-anal length (PoAl/ PrAL) was increased progressively in both treated groups while the growth of the body length was faster between the post anal length (tail-anus region) than between the pre-anal length ( anus -snout region) in high dose treated groups.

Table 4. The morphometric variables of body percentage (\%), obtained from Siganus rivulatus larvae during the experiment

\begin{tabular}{l|c|c|c|c|c|c|c|c}
\hline \multirow{2}{*}{$\mathrm{BP} \%$} & \multicolumn{9}{|c}{ Days post hatching } \\
\cline { 2 - 10 } & \multicolumn{2}{|c|}{$\mathbf{1 D P H}$} & \multicolumn{2}{c}{ 2DPH } & \multicolumn{2}{c}{ 3DPH } & \multicolumn{2}{c}{ 4DPH } \\
\hline Doses & $50 \mu \mathrm{g}$ & $100 \mu \mathrm{g}$ & $50 \mu \mathrm{g}$ & $100 \mu \mathrm{g}$ & $50 \mu \mathrm{g}$ & $100 \mu \mathrm{g}$ & $50 \mu \mathrm{g}$ & $100 \mu \mathrm{g}$ \\
\hline $\mathrm{HL} / \mathrm{TL}$ & $20.8 \%$ & $18.6 \%$ & $16.1 \%$ & $19.5 \%$ & $15.9 \%$ & $19.5 \%$ & $15.2 \%$ & $19.1 \%$ \\
\hline $\mathrm{TrL} / \mathrm{TL}$ & $21.2 \%$ & $18.9 \%$ & $24.7 \%$ & $18.3 \%$ & $22.3 \%$ & $17.7 \%$ & $21.6 \%$ & $17 \%$ \\
\hline $\mathrm{PrAL} / \mathrm{TL}$ & $42.1 \%$ & $37.6 \%$ & $40.8 \%$ & $37.9 \%$ & $38.1 \%$ & $37.2 \%$ & $36.8 \%$ & $37.2 \%$ \\
\hline POAL/TL & $57.9 \%$ & $61.5 \%$ & $60 \%$ & $62.1 \%$ & $61.7 \%$ & $62.6 \%$ & $63.2 \%$ & $63.9 \%$ \\
\hline POAL/ PrAL & $1.37 \%$ & $1.63 \%$ & $1.5 \%$ & $1.6 \%$ & $1.61 \%$ & $1.6 \%$ & $1.7 \%$ & $1.9 \%$ \\
\hline
\end{tabular}

BP\%: Body percentage, TL: Total length, HL: Head length, TrL: Trunk length, PrAL: Pre-anal length (head and trunk length), POAL :Post-anal length (tail length)

\section{DISCUSSION}

A variety of reproductive manipulation by hormonal induction of broodstock in captivity can cause significant differences between species in egg number and size Andrade-Talmelli et al. (2001). In this study, the diameter of Siganus rivulatus eggs produced from treated broodstock with low doses and high doses of injected ranged between $0.58 \mathrm{~mm}$ and $0.64 \mathrm{~mm}$ respectively. While the length of newly hatched larvae 
produced from treated broodstock with low doses and high doses of injected was varied between 1.59 and $1.975 \mathrm{~mm}$ respectively. Highly positive significant correlation was established between egg diameters and total larval lengths at yolk sac larvae stage produced from broodstock in high hormonal treated group (100 $\mu \mathrm{g} \mathrm{kg}{ }^{-1}$ LHRHa). Tabugo et al. (2013) studied the embryonic development of Siganus guttatus and found the ripe egg diameter was around $0.55 \mathrm{~mm}$ in desirable condition and the mean total length of the transparent newly hatched larvae was $1.7 \mathrm{~mm}$. Similarly, Gisbert et al. (2000) established a positive correlation between egg size and total length (TL), body weight (BW), yolk sac volume of newly hatched larvae and survival of early stages of Siberian sturgeon (Acipenser baeri) under small scale hatchery conditions.

Fahmy (2019) accomplished improvement in egg number, size, fertilization and hatching percentage of Siganus rivulatus using high dose $\left(100 \mu \mathrm{kg}^{-1}\right)$ of Luteinizing Hormone Releasing Hormone analogue (LHRHa) and reported a positive significant correlation between injection dose and egg quality. Rideout $\boldsymbol{e t}$ al. (2004) also reported a significant positive correlation in different fish species between the size of the newly hatched larvae and egg size at incubation period. The present result postulates that the differences in the egg and larval measurements are attributed to the high dose (100 $\mu g \mathrm{~kg}^{-1}$ LHRHa) injection.

The cleavage patterns of cell division reported in this study were concordant with the ones described by Tabugo et al. (2013) in normal reared larvae (Siganus guttatus, Bloch 1787). In comparison, they found that embryonic developmental stages were completed at 21 $\mathrm{h}$ and the embryos were hatched after $22-24 \mathrm{~h}$ post spawning at $27-29^{\circ} \mathrm{C}$ while in the present study the embryonic developmental stages of Siganus rivulatus were completed and embryos were hatched in the same time but at $22 \pm 0.5^{\circ} \mathrm{C}$. Dunham (2004) demonstrated that the timing of ontogenetic development within species is based on temperature which may have accelerated the rate of embryonic development. Various researchers had reported on the spectacular effect of temperature on the rate of the embryonic development and larval growth (Mommsen, 2001; Martell et al. 2005), energy utilization Finn et al. (2002), yolk-sac consumption Fukuhara (1990). So, the acceleration of the embryonic development in the present study may be due to the different doses of LHRHa injections as one of influential environmental factor.

In the head region of Siganus rivulatus, there was a significant positive growth pattern during the first developmental stages in specimens of the high dose treated group. During this period, the larvae were more dependent on endogenous feeding and the oral region was shifted from a ventral to a terminal position apparently synchronizing with functionally need to exogenous food. Souza et al. (2016) reported that the head region exhibited positive allometry relative to standard length that must be due to the growth of the brain case; this pattern suggests that the ability of larvae to capture prey may depend on development of bones in the oral region. Likewise, (Osse and Van-den Boogart, 2004) studied the transition in ontogenetic priorities in the head region during early development and found that during the endogenous nutrition period a positive allometry of head region was observed. This was related to vital functions such as brain mass development, development of bones in the oral region and branchial respiration. In the present study, head length proportion to the total length represented only $15.2 \%$ at low dose injection group and $19.16 \%$ in high dose injection group at the end of the larvae yolk sac stage. In the present study, these changes in percentages in the head length proportion to the larval total length were associated with the stepwise some morphological changes. As Gisbert (1999) reported that there were morphological changes that relevant to both brain mass and bones developments oral region 
even before they are functionally needed. The newly hatched larvae required developing the most essential organs for primary functions to survive. The present study point out that the growth of head length in higher hormone concentration was faster than its length in lower one which may serve and matches the vital function. In the trunk region, there was a reciprocal relationship with the higher hormone injection group showing a lower growth rate $(b=0.237)$ as compared to the low injection group $(b=0.527)$ during the yolk sac larval development period up to 4 days post hatching (DPH). However, both growth pattern results were negative. These results were dose-dependent and there was no evidence of growth priorities of the trunk in the larval yolk sac stage produced from both treated groups of broodstocks injected with either high or low concentration dose during the first development stage. Komsari et al. (2018) reported that the growth pattern in giraffe cichlid fish Nimbochromis venustusa was negative allometry up to $9 \mathrm{DPH}$ then turned to positive during different developmental stages. (Gisbert and Doroshov, 2006) found the same growth pattern of the trunk length from the body segments during the first yolk sac larval development period in A. medirostris. In the tail region, the results showed a positive allometric growth pattern of the tail and there were an equipotent in the growth coefficients differences between the two treated groups. Kovác et al. (1999) and (Yúfera and Darias, 2007) have made it clear that these differential development were matching the immediate vital functional demands throughout early life and can be an adaptation to its lifestyle for species survival. (Osse and Van-den Boogaart, 2004) illustrated that a positive allometric growth pattern of tail length improved swimming ability, reduced energetic costs and optimized the larval transport. Asgari et al. (2013a) found body shape variation during early life events and the priorities during early growth revealed consequent development of the anterior and posterior body part to improve swimming ability and food capture. Similarly, the present work showed growth length of the body segments during the yolk sac larval development period promoting allometric quantitative morphometric growth acceleration of head and tail regions in relation to total length which varied between the two groups of injection. The differences in the growth rates were directly proportional to the dose of injection. The high dose $\left(100 \mu \mathrm{gg}^{-1}\right)$ of LHRHa showed a significant positive high morphometric growth acceleration of head and tail segments as compared to the low dose. On the other hand, there was a reduction in growth coefficients in low dose injected broodstock which indicates a shift in growth priorities. Marked increased growth coefficients of the anterior and posterior parts in the larvae's bodies were observed in high dose (100 $\mu \mathrm{g} \mathrm{kg}^{-1}$ LHRHa) injected broodstock compared to those injected with a low dose (50 $\mathrm{g} \mathrm{kg}^{-1}$ LHRHa). This might ensure better survival chances of the larvae, increased the efficiency in prey capture and the agility to escape from predators.

\section{CONCLUSION}

The present work shows the superiority of high dose $\left(100 \mu g \mathrm{~kg}^{-1}\right)$ LHRHa in the allometric growth rate of Siganus rivulatus under controlled laboratory conditions. This work might be a baseline study to build on. Further studies might be warranted, to establish different doses of LHRLa injections that may help to improve the rearing of this species in hatchery and make it suitable for aquaculture and fishery industry by increasing the growth coefficients and shortening the incubation period.

\section{REFERENCES}

Andrade-Talmelli, E. F.; Kavamoto, E. T.; Romagosa, E. and Fenerich-Verani, N. (2001). Embryonic development of the 'piabanha', Brycon insignis, Steindachner, 1876 (Pisces; Characidae). Boletim do Instituto de Pesca., 27 (1): 21-28. 
Asgari, R.; Eagderi, S.; Rafiee, G.; Poorbagher, H.; Agh, N. and Eshaghzadeh, H. (2013a). Body shape changes during the early development of the Beluga (Huso huso). Int. J. Aquat. Biol., 1(1): 1-5.

Asgari, R.; Rafiee, G.; Eagderi, S.; Noori, F.; Agh, N.; Poorbagher, H. and Gisbert, E. (2013b). Ontogeny of the digestive enzyme activities in hatchery produced Beluga (Huso huso). Aquaculture, 416: 33-40.

Asgari, R.; Rafiee, G.; Eagderi, S.; Shahrooz, R.; Poorbagher, H. and Agh, N. (2014). Ontogeny of the digestive system in hatchery produced Beluga (Huso huso Linnaeus, 1758); a comparative study between Beluga and genus Acipenser. Aquac. Nutr., 20 (6): 595-560.

Çoban, D.; Suzer, C.; Yıldırım, Ş.; Saka, Ş. and Firat, K. (2012). Morphological Development and Allometric Growth of Sharpsnout Seabream (Diplodus puntazzo) Larvae. Turkish J. Fish. Aquat. Sci., 12: 883-891.

Comabella, Y.; Azanza, J.; Hurtado, A.; Canabal, J. and García-Galano, T. (2013). Allometric growth in Cuban gar (Atractosteus tristoechus) larvae. Univ. Sci., 29 (3): 301-315.

Dunham, R. A. (2004). Aquaculture and Fisheries Biotechnology: Genetic Approaches. Second ed. CABI Publishing, Wallingford, UK.

Fahmy, A. F. (2019). Improvement of spawning in Siganus rivulatus: the impact of different LHRHa doses, spawning methods and sex ratio on spawning performance and egg quality. Egypt. J. Aquat. Biol. Fish., 23(2): 505- 515.

Finn, R. N.; Rønnestad, I.; van der Meeren, T. and Fyhn, H. J. (2002). Fuel and metabolic scaling during the early life stages of Atlantic cod Gadus morhua. Marine Ecol. Progress Series, 24: 217-234.

Fuiman, L. A. (1983). Growth gradients in fish larvae. J. Fish. Biol. 23, 117-123.

Fukuhara, O. (1990). Effects of temperature on yolk utilization, initial growth, and behaviour of unfed marine fish-larvae. Marine Biol., 106 (2): 169-174.

Gilbert, S. F. and Bolker, J. A. (2003). Ecological developmental biology: preface to the symposium. Evol. Dev., 5: 3-8.

Gisbert, E. (1999). Early development and allometric growth patterns in Siberian sturgeon and their ecological significance. J. Fish. Biol., 54: 852-862.

Gisbert, E. and Doroshov, S. I. (2006). Allometric growth in green sturgeon larvae. J. Appl. Ichthyol., 22: 202-207.

Gisbert, E.; Williot, P. and Castello-Orvay, F. (2000). Influence of egg size on growth and survival of early stages of Siberian sturgeon (Acipenser baerii) under small scale hatchery conditions. Aquaculture, 183:83-94.

Hasanpour, S.; Eagderi, S.; Pourbagher, H.; Farahmand, H. and Bahrami-Ziarani, M. (2015a). Body shape changes of hatchery-reared triploid sturgeon (Acipenser baeri) $\mathrm{x}$ (Huso huso) during early development using geometric morphometric technique. AACL Bioflux, 8(3): 398-403.

Khemis, I. B.; Gisbert, E.; Alcaraz, C.; Zouiten, D.; Besbes, R.; Zouiten, A.; Masmoudi, A.S. and Cahu, C. (2013). Allometric growth patterns and development in larvae and juveniles of Thick-Lipped Grey Mullet Chelon labrosus Reared in Mesocosm Conditions. Aquac. Res., 44: 1872-1888.

Kimmel, C. B.; Ballard, W. W.; Kimmel, S. R.; Ullman, B. and Schilling, T .F. (1995). Stages of embryonic development of the zebrafish. Dev. Dynamics, 203: 253-310.

Komsari, M. S.; Salehi, M.; Chorehi, M. M.; Eagderi, S. and Sabet, H. M. (2018). Developmental morphology and growth patterns of laboratory-reared giraffe cichlid, Nimbochromis venustus Boulenger, 1908. Int. J. Aquat. Biol. 6(3): 170-178. 
Koumoundouros, G.; Divanach, P. and Kentouri, M. (1999). Ontogeny and allometric plasticity of Dentex dentex (Osteichthyes: Sparidae) in rearing conditions. Marine Biol., 135: 561-572.

Kováč, V.; Copp, G .H. and Francis, M. (1999). Morphometry of the stone loach, Barbatula barbatula: do mensural characters reflect the species life history thresholds?. Environ. Biol. Fish., 56: 105-15.

Leis, J. M. and T. Trnski (1989) Explanation of format. In "The Larvae of Indo-Pacific Shorefishes" Univ. Hawaii Press, Hawaii, pp. 8-14.

Marimuthu, K. and Haniffa, M. A. (2007). Embryonic and larval development of the striped snakehead Channa striatus. Taiwania, 52. (1): 84-92.

Martell, D. J.; Kieffer, J. D. and Trippel, E .A. (2005). Effects of temperature during early life history on embryonic and larval development and growth in haddock. J. Fish. Biol. 66: $1558-1575$.

Martínez-Montaño, E.; González-Álvarez, K.; Lazo, J. P.; Audelo-Naranjo, J. M. and Vélez-Medel, A. (2014). Morphological development and allometric growth of yellowtail kingfish Seriola lalandi V. larvae under culture conditions. Aquacult. Res. 47, 1277-1287.

Mehanna, S. F.; Mohammad, A. S.; El-Mahdy, S. M. and Osmann, Y. A. (2018). Stock assessment and management of the rabbit fish Siganus rivulatus from the southern Red sea, Egypt. Egyp. J. Aquat. Biol. Fish., 22. (5):313-319.

Mommsen, T. P. (2001). Paradigms of growth in fish. Comp. Biochem. Physiol. 129B, 20721910.

Moshayedi, F.; Eagderi, S. and Rabbaniha, M. (2017). Allometric growth pattern and morphological changes of green terror Andinoacara rivulatus (Günther, 1860) (Cichlidae) during early development: Comparison of geometric morphometric and traditional methods. Iran. J. Fish. Sci., 16.(1): 222-237.

Osse, J .W. and Van-den Boogaart, J. G. (1995). Fish larvae, development, allometric growth and the aquatic environment. ICES Marine Sci. Symp., 201: 21-34.

Osse, J. W. and Van-den Boogaart, J. G. (2004). Allometric growth in Fish larvae: timing and function. In: Govoni, J.J. (Ed). The Development of form and function in fishes and the question of larval adaptation. American Fisheries Society Symposium 40, Bethesda, MD, USA. pp. 167-194.

Parra, G. and Yu'fera, M. (2001). Comparative energetic during early development of two marine fish species, Solea senegalensis (Kaup) and Sparus aurata (L.). J. Exp. Biol., 204: $2175-2183$.

Puvaneswari, S. K.; Marimuthuv K.; Karuppasamyv R. and Haniffav M. A. (2009). Early embryonic and larval development of Indian catfish, Heteropneustes fossilis. Eur. Asian J. Biol. Sci., 3: 84-96.

Rideout, R. M.; Trippel, E. A. and Litvak, M. K., (2004). Predicting haddock embryo viability based on early cleavage patterns. Aquaculture, 230, 215-228.

Souza, G.; Melo, E. J.; Caramaschi, E. P.; Andrade, D .R. and Monteiro, L. R. (2016). Early development and allometric growth patterns of the grumatã (Prochilodus vimboides Kner, 1859) Zygote, 24: 428-441.

Tabugo, S. R.; Sendaydiego, J. P.; Requieron, E. A. and Dimalen, M. D. (2013). Embryonic developmental stages in cultured rabbitfish (Siganus guttatus, Bloch 1787). Int. Res. J. Biol. Sci., 1(8): 65-70.

Wahbi, O. M.; El-Greisy, Z. A. and El-Sayed, H. S. (2017). Reproductive Performance of Sea Bream (Sparus aurata) Induced with Two Different Hormone Protocols with Respect to the Effect on Gonadotrophic Cells. J. Biol. Sci., 17: 278-287.

Yúfera, M. and Darias, M. J. (2007). The onset of exogenous feeding in marine fish larvae. Aquaculture, 268: 53-63. 